University of Nebraska - Lincoln

DigitalCommons@University of Nebraska - Lincoln

Faculty Papers and Publications in Animal

Science

Animal Science Department

2004

\title{
Consumer Visual Preference and Value for Beef Steaks Differing in Marbling Level and Color
}

\author{
K. M. Killinger \\ University of Nebraska-Lincoln \\ Chris R. Calkins \\ University of Nebraska-Lincoln, ccalkins1@unl.edu \\ W. J. Umberger \\ University of Nebraska-Lincoln \\ D. M. Feuz \\ University of Nebraska-Lincoln \\ Kent M. Eskridge \\ University of Nebraska-Lincoln, keskridge1@unl.edu
}

Follow this and additional works at: https://digitalcommons.unl.edu/animalscifacpub

Part of the Animal Sciences Commons

Killinger, K. M.; Calkins, Chris R.; Umberger, W. J.; Feuz, D. M.; and Eskridge, Kent M., "Consumer Visual Preference and Value for Beef Steaks Differing in Marbling Level and Color" (2004). Faculty Papers and Publications in Animal Science. 582.

https://digitalcommons.unl.edu/animalscifacpub/582

This Article is brought to you for free and open access by the Animal Science Department at DigitalCommons@University of Nebraska - Lincoln. It has been accepted for inclusion in Faculty Papers and Publications in Animal Science by an authorized administrator of DigitalCommons@University of Nebraska - Lincoln. 


\title{
Consumer visual preference and value for beef steaks differing in marbling level and color ${ }^{1}$
}

\author{
K. M. Killinger*, C. R. Calkins ${ }^{* 2}$, W. J. Umberger $\dagger$, D. M. Feuz $\dagger$, and K. M. Eskridge \\ *Animal Science Department, $†$ Department of Agriculture Economics, and \\ $\ddagger$ Department of Biometry, University of Nebraska, Lincoln 68583
}

\begin{abstract}
To determine visual preference and value for fresh beef steaks differing in marbling level and color, consumers in Chicago and San Francisco ( $\mathrm{n}=124$ per city) evaluated two pairs of steaks in a retail case. Steaks differing in marbling level (Modest/ Moderate vs. Slight) and color (bright, cherry-red vs. dark red) were purchased at retail stores in each city. Consumers selected their preferred steak in each pair, described their selection criteria, and provided the price they were willing to pay for each of the four steaks. There was a difference in visual preference in each city, with most consumers preferring $(P<0.01)$ low (Slight) over high (Moderate/Modest) marbling; however, more $(P<0.01)$ consumers in Chicago $(86.7 \%)$ preferred low marbling than in San Francisco (67.0\%). Selection criteria were categorized into five groups: marbling, fat, color, appearance, and palatability. Marbling was mentioned by $65.4 \%$ of consumers who preferred high marbling, whereas $64.9 \%$ of consumers who preferred low marbling mentioned fat as a selec-
\end{abstract}

tion criterion. Bright, cherry-red color was preferred by a higher $(P<0.01)$ percentage of consumers in both Chicago and San Francisco (67.6 and 76.5\%, respectively). Color was mentioned both by consumers who preferred bright, cherry-red color (64.8\%) and those who preferred dark red color (63.9\%). All preference groups were willing to pay more for their preferred steak $(P<0.01)$, but consumers who preferred low marbling were willing to pay more $(P<0.01)$ for their preferred steak than consumers who preferred high marbling. Consumers who preferred bright, cherryred color were willing to pay more $(P<0.01)$ for their preferred steak than consumers who preferred dark red color. Consumers who preferred low marbling seemed to desire lean products, and consumers who preferred high marbling seemed to desire products with high eating quality. In this study, consumers were willing to pay more to purchase their preferred product; however, most consumers preferred low marbling and bright, cherry-red color.

Key Words: Beef, Consumer Preferences, Market Research

(C2004 American Society of Animal Science. All rights reserved.

J. Anim. Sci. 2004. 82:3288-3293

\section{Introduction}

Visual appearance of retail beef influences consumer purchases. Consumers have consistently rated leanness as an important selection criterion when evaluating retail steaks (Forbes et al., 1974; Jacobs et al., 1977). Marbling contributes to the visual appraisal of fat content; therefore, consumer perception of marbling could be negative as it increases overall fat in the product, which is not as "trimmable" as s.c. and intermuscular fat. Savell et al. (1989) found a consumer preference for U.S. Select-grade beef; however,

\footnotetext{
${ }^{1}$ Published as Paper No. 14012, Journal Series, Nebraska Agric. Res. Div., Univ. of Nebraska, Lincoln 68583-0908.

${ }^{2}$ Correspondence: A213 Animal Science (phone: 402-472-6314; fax: 402-472-6362; e-mail: ccalkins1@unl.edu).

Received February 28, 2003.

Accepted July 21, 2004.
}

marbling has long been used as factor in the USDA beef quality grading system as a visual indicator of lean quality (USDA, 1997), and consumers might consider marbling indicative of quality and palatability. Certainly, consumer preferences change over time. In studies comparing high and low marbling levels, Dunsing (1959) found that consumers preferred higher marbling levels, and $20 \mathrm{yr}$ later, Forbes et al. (1974) indicated that most consumers considered degree of marbling an important selection criterion, but preferred lower marbling levels.

Consumers have indicated that color is an important selection criterion (Savell et al., 1989). Color has been used by consumers as an indicator of freshness and eating potential of the cooked product (Forbes et al., 1974). Moreover, Jeremiah et al. (1972) reported that consumers found beef that was neither too pale nor too dark the most desirable.

Because consumer preferences for visual appearance of beef change over time, knowledge of current 
consumer preferences and the value of marbling and color could help the beef industry provide visually appealing products to consumers. Therefore, the objectives of this study were to determine 1) current consumer preferences for retail beef steaks differing in marbling level and color, 2) the selection criteria used by consumers to choose their preferred steaks, and 3) how much more consumers were willing to pay for their preferred steaks.

\section{Materials and Methods}

\section{Screening of Panelists}

Consumers in Chicago and San Francisco were screened over the telephone to determine whether they qualified for the study. A professional consumer marketing firm was employed to solicit participants for the study. To qualify, a consumer had to be the primary grocery shopper in the household or share shopping duties equally with another member of the household. In addition, consumers had to be between 19 to $59 \mathrm{yr}$ old and willing to consume beef. Consumers and their immediate families could not be employed in any portion of the meat animal industry, market research, advertising, or news reporting. Qualified consumers were scheduled in groups of 12 for one of 12 evaluation sessions held in each city (four sessions per day for three consecutive days).

In each city, 124 consumers participated in the study. Participation in evaluation sessions ranged from 6 to 12 consumers who were $35 \mathrm{yr}$ or older, and most consumed beef in their homes three to four times per week. In Chicago, $82.3 \%$ of consumers were female and $97.5 \%$ were Caucasian, whereas in San Francisco $77.4 \%$ were female and $81.9 \%$ were Caucasian.

\section{Selection of Visual Evaluation Steaks}

All steaks used for visual evaluation were purchased fresh at local retail stores. If the steaks maintained a visual appearance typical for retail stores, they were stored overnight in a refrigerator and used for more than one day of display (no steak was used for more than $3 \mathrm{~d}$ ). For the marbling comparison, high (Modest and Moderate) and low (Slight) marbled strip steaks were purchased. For the color comparison, dark-red and bright cherry-red steaks were purchased to provide a contrast in color. Color was subjectively assessed by experienced evaluators. In Chicago, ribeye steaks were used for the color comparison because dark-cutting steaks were available and provided a stark contrast in color; however, the dark-cutting steaks did have higher degrees of marbling (Small and Modest) than the bright, cherry-red steaks (Slight degree of marbling). In San Francisco, no dark-cutting ribeye steaks were found, so strip steaks were used to represent the color contrast.

Steaks were packaged similarly, and efforts were made to select steaks that were similar in size, thick- ness, and trim level so that the steaks differed only in marbling or color. If steaks differed noticeably in an attribute other than marbling or color, a sign was placed in the display case asking consumers to ignore that attribute. Steaks were assigned four-digit random codes for each evaluation session, and were displayed in a retail display case at $4^{\circ} \mathrm{C}$ for visual evaluation. In Chicago, the retail case (Arctic Air Refrigerator, model R22CW6; WCI Division of Broich Enterprises, Inc., Eden Prairie, MN) was equipped with high-fidelity "pink cast" light bulbs ( $40 \mathrm{~W}$ Promolux Platino 3 F040 T8; Promolux Lightning Int., Shawnigan Lake, British Columbia, Canada), and in San Francisco, the retail case (True Manufacturing Co., O'Fallon, MO) was equipped with Envir-O-light bulbs (F40T12/CW/ EG, 5000 K, Radiant Lamp Co., Philadelphia, PA).

\section{Evaluation Session Procedures}

Consumers who qualified and agreed to participate were mailed a consent form and a survey that ascertained information on their eating preferences, meat purchasing behaviors, and other demographic characteristics. Upon arrival at the facility, consumers were paid for their participation ( $\$ 25$ in Chicago and $\$ 35$ in San Francisco). Consumers were compensated amounts comparable to other test market facilities in the respective city. Consumers also completed a meat knowledge survey. After completing the survey, consumers were given a visual evaluation form and asked to evaluate the two pairs of steaks in the retail case. Consumers selected their preferred steak in each pair and listed the selection criteria used to choose their preferred steak. Selection criteria were unprompted. Additionally, consumers provided the price per 0.45 $\mathrm{kg}$ that they were willing to pay for each of the four steaks.

\section{Chemical Analyses}

In San Francisco, steaks used for visual evaluation were frozen in a commercial freezer and shipped frozen to the University of Nebraska, Lincoln. Steaks were thawed, trimmed of external fat, cut into small pieces, and powdered in liquid $\mathrm{N}$ using a Waring blender (Dynamics Corp. of America, New Hartford, CT). Duplicate samples were analyzed for moisture and ash using a Leco thermogravimetric analyzer (Leco Corp., St. Joseph, MI). For lipid content, duplicate samples were distilled in anhydrous ether for $72 \mathrm{~h}$ using the Soxhlet method (AOAC, 1990).

\section{Statistical Analyses}

Consumer evaluations providing conflicting information that could not be interpreted on the visual evaluation forms were removed from the analysis. Therefore, 220 consumer evaluations were used in the analysis (105 consumers in Chicago and 115 in San Francisco). A normal approximation for binomial data 
Table 1. Consumer visual preference for high- and lowmarbled beef strip steaks ${ }^{\mathrm{a}}$

\begin{tabular}{lcc}
\hline \hline Visual preference & Chicago, $\%$ & San Francisco, \% \\
\hline High marbling & $13.3^{\text {by }}$ & $33.0^{\mathrm{bz}}$ \\
Low marbling & $86.7^{\mathrm{cy}}$ & $67.0^{\mathrm{cbz}}$ \\
\hline
\end{tabular}

${ }^{\text {a} H i g h ~ m a r b l i n g ~}=$ Modest and Moderate degrees of marbling, and Low marbling $=$ Slight degree of marbling.

b,c Within a column, least squares means without a common superscript letter differ $(P<0.01)$.

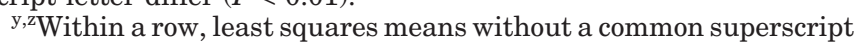
letter differ, $P<0.01$.

was used for each city to test whether the proportion of the consumers who preferred low marbling and those who preferred bright, cherry-red color were equal to 0.5. A $\chi^{2}$ test and the frequency procedure of SAS (SAS Inst., Inc., Cary, NC) were used to test whether preference proportions were affected by city, selection criteria, and demographics. Price data were analyzed, using the mixed model procedure, as a splitplot design with preference as the whole plot and marbling level/color as the split-plot. Factors included in the model were city (C), evaluation session (S), panelist $(\mathrm{P})$, preference for marbling/color $(\mathrm{M})$ and steak type (T; high and low marbled or dark red and bright, cherry-red), and the sources in the ANOVA were $\mathrm{C}, \mathrm{S}$ within $\mathrm{C}, \mathrm{M} \times \mathrm{C}, \mathrm{M} \times \mathrm{S}$ within $\mathrm{C}, \mathrm{P}$ within $\mathrm{C} \times \mathrm{S} \times \mathrm{M}$ (whole plot error term), $\mathrm{T} \times \mathrm{C}, \mathrm{T} \times \mathrm{S}$ within $\mathrm{C}, \mathrm{T} \times \mathrm{M}$, $\mathrm{T} \times \mathrm{M} \times \mathrm{C}$, and $\mathrm{T} \times \mathrm{M} \times \mathrm{S}$ within $\mathrm{C}$. All factors were considered fixed, with the exception of panelist and evaluation session, which were considered as random effects. Least squares means were calculated for differences between steaks differing in marbling level and color using paired $t$-tests (PDIFF option of SAS). Additionally, responses on surveys were analyzed for differences between cities and between preference groups using a $\chi^{2}$ test.

\section{Results and Discussion}

In both cities, most consumers preferred $(P<0.01)$ low-marbled steaks (Table 1). These findings were consistent with Forbes et al. (1974), who found that Canadian consumers tended to visually prefer low-marbled steaks. Additionally, Savell et al. (1989) reported that consumers liked the leanness of U.S. Select beef. This trend has continued, as most consumers in this study preferred the leaner, low-marbled steak. In addition, the magnitude of visual preference was $(P<0.01)$ different between cities. In Chicago, $86.7 \%$ of consumers preferred low marbling, whereas $67.0 \%$ preferred low marbling in San Francisco.

City influenced consumer visual preferences, with consumers in San Francisco being more likely $(P<$ 0.05 ) to prefer the high-marbled steak than consumers in Chicago. In general, women were less $(P=0.04)$ likely (75.0 vs. $71.6 \%)$ to prefer high-marbled steaks (Umberger, 2001). Consumer survey responses also

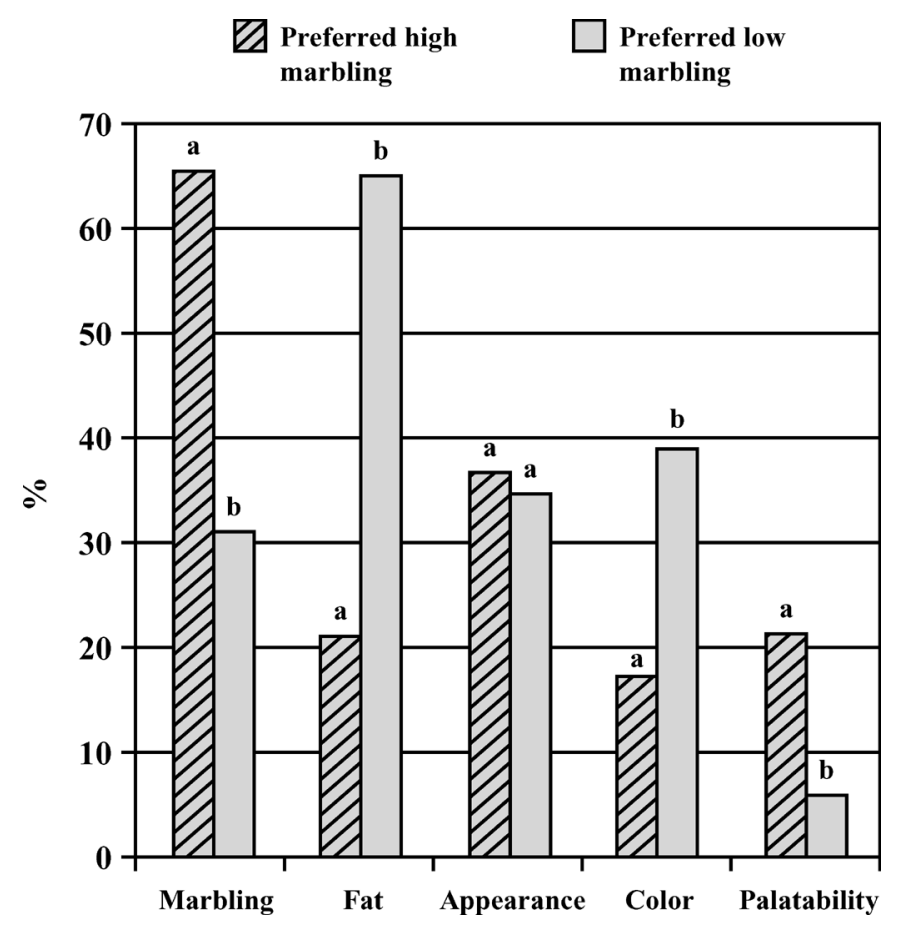

Figure 1. Percentage of selection criteria listed by each marbling (high marbling $=$ Modest and Moderate, and low Marbling = Slight) preference group. Within a selection criterion category, bars without a common letter differ, $P<0.01$.

provided insight for potential reasons that differences were observed between cities. The highest percentage of consumers in each city responded that their shopping was driven by quality, and there was a difference $(P<0.05)$ in the magnitude of that response between cities (63.7\% in San Francisco vs. $46.2 \%$ in Chicago). Moreover, the type of beef product most frequently purchased by consumers was different $(P<0.01)$ between cities. The majority of consumers in San Francisco (65.0\%) most frequently purchased steak, but the majority of consumers in Chicago $(52.5 \%)$ most frequently purchased ground beef. Additionally, a higher $(P<0.05)$ percentage of consumers in San Francisco (32.3\%) ranked marbling third, or higher, as an important characteristic used as a selection criterion compared with $20.9 \%$ in Chicago. With consumers in San Francisco purchasing steak more often than those in Chicago, consumers in San Francisco may have been more familiar with selection criteria used to purchase steaks. Additionally, with a higher percentage of consumers in San Francisco being driven by quality factors when shopping, the consumers surveyed in San Francisco may have been more aware that marbling is used as a visual indicator of palatability in the USDA quality grading system.

Selection criteria provided by consumers were categorized into five main groups: marbling, fat, appearance, color, and palatability (Figure 1). Examples of comments sorted into each category were as follows: 
marbling (more/less marbling and even distribution of marbling), fat (leaner, fat easy to remove, and fat not excessive), appearance (fresher, thicker, size, and texture), color (dark, lighter, uniform, and dislike color), and palatability (looks tender, more flavor, juicier, and tastier).

Marbling was mentioned as a factor used in steak selection by $65.4 \%$ of consumers who preferred highmarbled steak, but only $31 \%$ of consumers who preferred low-marbled steak mentioned marbling. In contrast, $64.9 \%$ of consumers who preferred the low-marbled steaks mentioned fat as an important selection criterion, whereas only $21.2 \%$ of consumers who preferred the high-marbled steaks expressed that fat was an important selection criterion. It seems that consumers who preferred high marbling viewed i.m. fat as a positive attribute, and used marbling as a primary selection criterion when selecting steaks. Conversely, consumers who preferred low marbling used fat content as a selection criterion, and viewed marbling as a negative factor due to the increased overall fat content of the steak. Previous studies also indicated that consumers consider leanness an important selection criterion (Forbes et al., 1974; Jacobs et al., 1977; Savell et al., 1989). Consumers who listed marbling as a selection criterion were more likely to prefer high-marbled steaks, and consumers who mentioned fat as a selection criterion were less likely to prefer the high-marbled steaks (Umberger, 2001).

These observations were reinforced by the responses in the surveys as well. The definition of marbling was correctly identified by a higher $(P<0.10)$ percentage of consumers who preferred high marbling (30.8\%) than by consumers who preferred low marbling $(18.5 \%)$. A higher $(P<0.01)$ percentage of consumers who preferred high marbling (40.4\%) ranked marbling in the top three selection criteria that were important when purchasing beef compared with $22.2 \%$ of consumers who preferred low marbling. In contrast, $67.8 \%$ of consumers who preferred low marbling ranked fat third or higher as an important selection criterion when purchasing beef, which was higher $(P<0.01)$ than the percentage of consumers who preferred high marbling $(26.7 \%)$.

Consumer comments on selection criteria provided during the visual evaluation procedures were consistent with the comments on selection criteria in the survey based on their typical meat purchasing behavior. It seems that consumers who were more informed about marbling were more likely to use it as a selection criterion and prefer the high-marbled steak. Additionally, a higher $(P<0.05)$ percentage of consumers who preferred high marbling (73.1\%), as opposed to $53.4 \%$ of consumers who preferred low marbling, indicated that they would not apply flavoring products (marinades, steak sauce and/or spices) to steaks if the steaks were more flavorful by themselves. It was also interesting that consumers who preferred high marbling tended to prepare beef more frequently in their homes
Table 2. The value $( \pm \mathrm{SE})$ that consumers with different preferences for marbling level placed on high- and lowmarbled beef strip steaks based on visual evaluation $(\$ /$ $0.45 \mathrm{~kg})^{\mathrm{a}}$

\begin{tabular}{lcc}
\hline \hline Price & $\begin{array}{c}\text { High-marbled } \\
\text { steak }\end{array}$ & $\begin{array}{c}\text { Low-marbled } \\
\text { steak }\end{array}$ \\
\hline High-marbled steak & $\$ 3.80 \pm 0.24^{\mathrm{b}}$ & $\$ 2.86 \pm 0.14^{\mathrm{b}}$ \\
Low-marbled steak & $\$ 3.00 \pm 0.24^{\mathrm{c}}$ & $\$ 3.98 \pm 0.14^{\mathrm{b}}$ \\
Differential & $\$ 0.80 \pm 0.17^{\mathrm{y}}$ & $-\$ 1.12 \pm 0.10^{\mathrm{z}}$ \\
\hline
\end{tabular}

${ }^{\text {a}}$ High-marbled = Modest and Moderate degrees of marbling, and Low-marbled $=$ Slight degree of marbling.

${ }^{b, c}$ Within a column, least squares means without a common superscript letter differ, $P<0.01$.

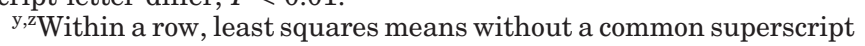
letter differ, $P<0.01$.

than consumers who preferred low marbling. Thus, it seems that consumers who prefer high marbling are interested in obtaining steaks that are acceptable in flavor without adding other ingredients.

Appearance was mentioned by a similar $(P=0.79)$ number of consumers who preferred high- and lowmarbled steaks. Although efforts were made to select steaks that differed in marbling but were very similar in other characteristics, consumers who preferred the low-marbled steaks mentioned color more $(P<0.01)$ often than consumers who preferred the high-marbled steaks (38.7 vs. $17.3 \%$, respectively). The researchers did not detect noticeable color differences when the steaks were purchased, but it is possible that some steaks may have darkened throughout the day of display. Perhaps differences in the amount of i.m. fat contributed to consumer perception of color between the two steaks. A higher $(P<0.01)$ percentage $(21.2 \%)$ of consumers who preferred the high-marbled steak mentioned palatability characteristics compared with consumers preferring the low-marbled steak (6.0\%). It seems that some consumers who preferred the highmarbled steak associated higher marbling levels with increased steak palatability. It is very likely that consumers who preferred high marbling were more interested in eating quality, whereas consumers who preferred low marbling were more concerned with fat content.

With regard to the value consumers placed on highand low-marbled steaks, there was a preference $\times$ marbling level interaction $(P<0.01$; Table 2$)$. Both preference groups, those who preferred high marbling and those who preferred low marbling, were willing to pay more $(P<0.01)$ for their preferred steak. Additionally, consumers who preferred low-marbled steaks were willing to pay more $(P<0.01)$ for their preferred steak than those who preferred high marbling. It seems that consumers who prefer low marbling felt more strongly about their preference and were willing to pay more for steaks that offered reduced fat content.

Prices provided by consumers did not necessarily reflect the retail value of the steaks. Coursey and 
Table 3. Consumer visual preference for dark-red and bright, cherry-red beef steaks

\begin{tabular}{lcc}
\hline \hline Visual preference & $\begin{array}{c}\text { Chicago, } \\
\%\end{array}$ & $\begin{array}{c}\text { San Francisco, } \\
\%\end{array}$ \\
\hline Preferred dark-red color & $32.4^{\mathrm{a}}$ & $23.5^{\mathrm{a}}$ \\
Preferred bright, cherry-red color & $67.6^{\mathrm{b}}$ & $76.5^{\mathrm{b}}$ \\
\hline
\end{tabular}

${ }^{\mathrm{a}, \mathrm{b}}$ Within a column, least squares means without a common superscript letter differ, $P<0.01$.

Smith (1984) noted that consumers were often unwilling to reveal their maximum willingness to pay for products when value was elicited using an auction procedure. Menkhaus et al. (1992) suggested that, when comparing two products, the differential between the bids submitted for the two products represents a true difference in value (more than the absolute bids themselves). Although the prices in this study were not ascertained using an auction, they were consistent with auction bids in a similar study (Killinger et al., 2004a,b).

For the high- and low-marbled steaks used in San Francisco, subjective evaluation of fat content was consistent with ether-extractable fat content, with the high-marbled steaks containing an average of $9.1 \pm$ $0.94 \%$ fat, which was higher $(P<0.01)$ than the value for the low-marbled steaks $(4.2 \pm 0.20 \%$ fat $)$. Highmarbled steaks also had lower $(P<0.01)$ moisture and ash content than low-marbled steaks.

When comparing beef color, there was a difference $(P<0.01)$ in color preference for each city (Table 3$)$. Consumers in both Chicago and San Francisco preferred steaks with bright, cherry-red color (67.6 and $76.5 \%$, respectively). Unlike the marbling comparison, the proportion of visual preference for color was similar $(P=0.14)$ between cities. Forbes et al. (1974) also found that most consumers preferred red or bright red lean; however, a small portion of the consumers in that study preferred dark red lean, and associated dark red color with aging and tenderness of the product.

Again, selection criteria mentioned by consumers were categorized into five groups: color, fat, marbling, appearance, and palatability (Figure 2). It is interesting to note that a similar $(P=0.91)$ percentage of consumers who preferred bright, cherry-red color and those who preferred dark red color mentioned color as a selection criteria (64.8 and $63.9 \%$, respectively). Therefore, color influences consumer preference, and consumers seek both bright cherry-red and dark-red beef.

A higher $(P<0.05)$ percentage of consumers $(41.5 \%)$ who preferred the bright, cherry-red color mentioned fat as a selection criteria compared with $26.2 \%$ of consumers who preferred dark color. Although the darkred (dark-cutting) steaks in Chicago had a higher degree of marbling, comments about fat as a selection criterion between consumers who preferred bright, cherry-red and dark red color did not seem to be af- $\square$ Preferred dark red $\square$ Preferred bright, cherry-red

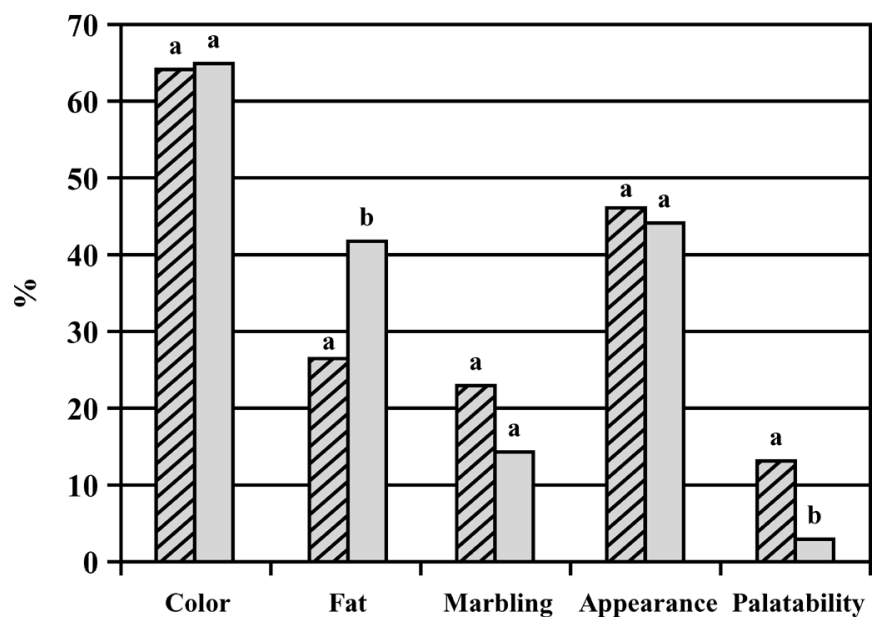

Figure 2. Percentage of selection criteria listed by each color preference group. A description of comments within each category is provided in the text. Within a selection criterion category, bars without a common superscript letter differ, $P<0.05$.

fected (results not shown). Lean color may have affected consumer perception of fat, even when fat levels were similar as was the case in San Francisco. For the color comparison steaks in San Francisco, subjective visual assessment of fat content was consistent with ether extractable fat content. Both the dark-red and bright, cherry-red steaks had similar $(P>0.50)$ fat (6.0 and $6.8 \%$, respectively), moisture $(71.3$ and $70.8 \%$, respectively), and ash (1.1 and $1.2 \%$, respectively) contents.

Information provided on the surveys was used to help characterize consumers with different visual preferences for color. A higher $(P<0.05)$ percentage of consumers who preferred bright, cherry-red color were Caucasian $(94.0 \%)$, whereas $81.0 \%$ of consumers who preferred dark red color were Caucasian. Hispanics preferred $(P<0.05)$ dark red color, and comprised $10.3 \%$ of consumers who preferred dark red color vs. $2.0 \%$ of consumers preferring bright, cherry-red color. Through examination of answers on the meat knowledge survey, consumers who preferred dark color seemed to be more knowledgeable about certain aspects of beef and meat preparation. Comparing consumers who preferred dark red color and consumers who preferred bright, cherry-red color, a higher $(P<$ $0.10)$ percentage of consumers who preferred dark color correctly identified the definition of marbling ( 29.5 and $18.2 \%$, respectively), the primal cut in which the New York strip steak is located (57.6 and 43.7\%, respectively), and an ingredient which will not tenderize meat in a marinade (74.6 and $62.0 \%$, respectively). Finally, a higher $(P<0.05)$ percentage of consumers who preferred bright, cherry-red color were extremely or very satisfied with the palatability of beef products 
Table 4. The value $( \pm S E)$ that consumers with different preferences for color placed on bright, cherry-red and dark-red beef steaks based on visual evaluation $(\$ / 0.45$ $\mathrm{kg})$

\begin{tabular}{lcc}
\hline \hline Price & $\begin{array}{c}\text { Preferred } \\
\text { dark-red } \\
\text { color }\end{array}$ & $\begin{array}{c}\text { Preferred bright, } \\
\text { cherry-red } \\
\text { color }\end{array}$ \\
\hline Dark red steak & $\$ 4.32 \pm 0.21^{\mathrm{a}}$ & $\$ 3.12 \pm 0.14^{\mathrm{a}}$ \\
Bright, cherry-red steak & $\$ 3.68 \pm 0.21^{\mathrm{b}}$ & $\$ 3.86 \pm 0.14^{\mathrm{b}}$ \\
Differential & $\$ 0.64 \pm 0.09^{\mathrm{y}}$ & $-\$ 0.74 \pm 0.06^{\mathrm{z}}$ \\
\hline
\end{tabular}

${ }^{\mathrm{a}, \mathrm{b}}$ Within a column, least squares means without a common superscript letter differ, $P<0.01$.

${ }^{\mathrm{y}, \mathrm{z}}$ Within a row, least squares means without a common superscript letter differ, $P<0.01$.

(45.9\%) compared with $27.9 \%$ of consumers who preferred the dark red color. A higher $(P<0.05)$ percentage of consumers who preferred dark color were identified in the satisfied and unsatisfied categories $(72.2 \%)$ compared with $53.5 \%$ of consumers who preferred bright, cherry-red color.

Marbling and appearance were used by a similar ( $P=0.13$ and 0.80 , respectively) percentage of consumers in both the bright, cherry-red and dark red color preference groups. A higher $(P<0.01)$ percentage of consumers (13.1\%) preferring dark red color mentioned palatability as a selection criterion, and $3.1 \%$ of consumers who preferred the bright, cherry-red color mentioned palatability. Perhaps, as in the study by Forbes et al. (1974), consumers preferring dark red color associate dark red color with increased tenderness; however, it has been shown that subjective visual color is not related to palatability characteristics (Jeremiah et al., 1972).

Consumer preference also influenced the price consumers were willing to pay for dark red and bright, cherry-red steaks $(P<0.01)$. Consumers who preferred the dark red color were willing to pay $\$ 0.64 / 0.45 \mathrm{~kg}$ more $(P<0.01)$ for the dark red steak, and consumers who preferred bright, cherry-red color were willing to pay $\$ 0.74 / 0.45 \mathrm{~kg}$ more $(P<0.01)$ for the bright, cherryred steak (Table 4). Consumers who preferred bright, cherry-red color were willing to pay more $(P<0.01)$ for their preferred steak than consumers who preferred dark red color. Thus, consumers who preferred bright, cherry-red color were more intent about their preference than consumers who preferred dark red color.

\section{Implications}

Consumers visually prefer both high- and low-marbled steaks and are willing to pay more for the preferred steak. Consumers who preferred low marbling are more intent about obtaining steaks with lower fat content. Therefore, target markets exist for high- and low-marbled steaks. Consumers preferring both darkred and bright, cherry-red steaks were willing to pay more for their preferred steak. Therefore, both color and marbling are important selection criterion.

\section{Literature Cited}

AOAC. 1990. Offical Methods of Analysis. 15th ed. Assoc. Off. Anal. Chem., Washington, DC.

Coursey, D. L., and V. L. Smith. 1984. Experimental tests of an allocation mechanism for private, public or externality goods. Scand. J. Econ. 86:468-484.

Dunsing, M. 1959. Visual and eating preferences of consumer household panel for beef from Brahman-Hereford crossbreds and from Herefords. Food Technol. 13:451-456.

Forbes, S. M. C., M. Vaisey, and R. Diamant. 1974. The relationships between consumer criteria for choosing beef and beef quality. Can. Inst. Food Sci. Technol. J. 7:130-135.

Jacobs, J. A., J. C. Miller, E. A. Sauter, A. D. Howes, A. A. Araji, T. L. Gregory, and C. E. Hurst. 1977. Bulls versus steers. II. Palatability and retail acceptance. J. Anim. Sci. 46:699-702.

Jeremiah, L. E., Z. L. Carpenter, and G. C. Smith. 1972. Beef color as related to consumer acceptance and palatability. J. Food Sci. 37:476-479.

Killinger, K. M., C. R. Calkins, W. J. Umberger, D. M. Feuz, and K. M. Eskridge. 2004a. A comparison of consumer sensory acceptance and value of domestic beef steaks and steaks from a branded, Argentine beef program. J. Anim. Sci. 82:3302-3307.

Killinger, K. M., C. R. Calkins, W. J. Umberger, D. M. Feuz, and K. M. Eskridge. 2004b. Consumer sensory acceptance and value for beef steaks of similar tenderness, but differing in marbling levels. J. Anim. Sci. 82:3294-3301.

Menkhaus, D. J., G. W. Borden, G. D. Whipple, E. Hoffman, and R. A. Field. 1992. An empirical application of laboratory experimental auctions in marketing research. Agric. Res. Econ. $17: 44-55$.

Savell, J. W., H. R. Cross, J. J. Francis, J. W. Wise, D. S. Hale, D. L. Wilkes, and G. C. Smith. 1989. National consumer retail beef study: Interaction of trim level, price and grade on consumer acceptance of beef steaks and roasts. J. Food Qual. 12:251-274.

Umberger, W. J. 2001. Consumer willingness-to-pay for flavor in beef steaks: An experimental economics approach. Ph.D. dissertation. University of Nebraska-Lincoln, Lincoln.

USDA. 1997. United States Standards for Grades of Carcass Beef. Agric. Marketing Serv., USDA, Washington, DC. 